Jurnal Teknologi, bil. 26, Jun 1997 hlm. 75-81

(c) Universiti Teknologi Malaysia

\title{
ANTENA TERCETAK MENGALIR LAMPAU MODEL TERKECIL UNTUK KEGUNAAN TERHAD-RUANG
}

\author{
MAZLINA ESA \\ Panel Radio dan Akustik \\ Fakulti Kejuruteraan Elektrik \\ Universiti Teknologi Malaysia \\ KB 791, 80990 Johor Bahru \\ Johor Darul Ta'zim, Malaysia \\ MICHAEL JOHN LANCASTER \\ Electronic Materials and Devices (EMD) Research Group \\ School of Electronic and Electrical Engineering \\ The University of Birmingham \\ Edgbaston, Birmingham \\ B15 2TT, United Kingdom
}

\begin{abstract}
Abstrak. Sebilangan antena dwikutub mengalir lampau telah dibikin dan diuji. Bahan mengalir lampau membolehkan antena dimodelkecilkan dengan kecekapan yang diperbaiki. Geometri dwikutub dibentuk sebagai talian liku untuk mencapai pemodelkecilan. Hasil ukuran dan selakuan menunjukkan bahawa pemodelkecilan berjaya dihasilkan oleh tatarajah tersebut di samping mengekalkan frekuensi kendalian rendah 3.0GHz. Semua dwikutub liku mengalir lampau ini didapati kecil secara elektrik.
\end{abstract}

\section{KEBERALIRAN LAMPAU}

Pada 1911, Kamerlingh Onnes menemui fenomenon keberaliran lampau semasa membuat ujikaji rintangan AT dengan penyusutan suhu [1]-[3]. Fenomenon ini diperihalkan sebagai: "di bawah suhu genting, suatu bahan memasuki keadaan baru, di mana dengan mengambilkira hak milik elektriknya yang luar biasa, keadaan ini bolehlah disebut keadaan mengalir lampau". Semasa ujikaji tersebut, rintangan suatu dawai raksa mendadak turun menjadi sifar pada suhu hampir $4 \mathrm{~K}$. Suhu sedemikian disebut suhu peralihan atau suhu genting, iaitu $T_{c}$. Tiga tahun kemudian, ternyata bahawa fenomenon demikian boleh musnah dengan menaikkan suhu bahan, mengenakan ketumpatan arus terlalu tinggi melalui bahan, ataupun meletakkan bahan di dalam medan magnet yang terlalu kuat.

Pada 1933, Walther Meissner dan Robert Ochsenfeld membuat penemuan penting mengenai kebolehan pengalir lampau membuang fluks, yang dikenali sebagai kesan Meissner [1]-[3]. Suatu bahan diamagnet adalah bahan yang cuba meminimum ketumpatan fluks magnet, B, di dalamnya sendiri, apabila diletakkan di dalam medan magnet. Oleh itu, suatu pengalir lampau, yang cuba mengekalkan keadaan ketumpatan fluks magnet sifar dalam lingkungannya, disebut diamagnet lengkap. Kesan Meissner adalah tunjukan bahawa keberaliran lampau adalah lebih daripada hanya keberaliran sempurna. 
Ringkasnya, keadaan aliran lampau mengandungi dua hak milik makroskop tak bersandar. Pertama, ia mempunyai keberintangan elektrik AT sifar di bawah suhu genting seperti ditunjukkan dalam Rajah 1. Kedua, ia mempunyai diamagnetisme hampir-sempurna dengan kehadiran medan magnet lemah. Hak milik ini menghasilkan pembuangan fluks magnet daripada bahagian dalaman pengalir lampau, kecuali dalam kawasan nipis pada permukaan. Pembuangan ini dirujuk sebagai kesan Meissner, kecuali pada bahagian nipis di permukaan, sepertimana perbincangan sebelum ini. Hak milik inilah yang mengenal beza suatu pengalir lampau yang mempunyai keberintangan sifar (yang hanya benar pada AT) daripada pengalir sempurna.

Selain itu, kesan Josephson wujud pada simpang Josephson peranti pengalir lampau [3]. Simpang ini boleh terhasil apabila dua lapisan pengalir lampau terapit oleh lapisan nipis penebat atau pengalir biasa di antara keduanya. Kesan Josephson meliputi kesan AT, kesan AU dan kesan magnet. Kesan AT terhasil apabila voltan AT merintangi simpang adalah sifar dan kemungkinan arus AT mengalir lampau mengalir melalui simpang. Kesan AU terhasil apabila arus AT mengalir lampau ini melebihi arus genting dan voltan AT merintangi simpang menjadi bukan-sifar. Ini menjana arus AU dengan frekuensi yang dikenali sebagai Josephson. Kesan magnet terhasil apabila arus genting di simpang bervoltan sifar, yang merupakan fungsi medan magnet, dikenakan terhadap simpang.

Penemuan suatu bahan yang menjadi mengalir lampau pada suhu genting melebihi $30 \mathrm{~K}$ telah dilakukan oleh K. Alex Müller dan J. Georg Bednorz pada 1986 [1]-[3]. Bahan ini adalah campuran lanthanum, barium, kuprum dan oksigen, kemudiannya dikenalpasti sebagai sebatian $\mathrm{La}_{1.85} \mathrm{Ba}_{0.15} \mathrm{CuO}_{4}$. Penemuan ini mencetuskan usaha besar-besaran di seluruh dunia ke arah penemuan pengalir-pengalir lampau dengan suhu genting yang jauh lebih tinggi. Sebelum 1986, helium cecair (suhu mendidih 4.2K) merupakan bahan pendingin yang cukup sejuk dan yang biasa digunakan untuk semua ujikaji mengalir lampau. Kekurangan bahan pengalir lampau suhu rendah tersebut termasuklah suhu genting rendah yang tidak praktik dan kos tinggi berkaitan helium cecair serta keperluan kemudahan kriogenik tahap berbilang yang cukup rumit. Semua pengalir lampau yang ada sehingga tempoh ini disebut pengalir suhu rendah.

Bahan mengalir lampau pertama dengan suhu genting yang cukup tinggi untuk didinginkan oleh nitrogen cecair (yang mendidih pada $77 \mathrm{~K}$ ) telah dipertunjukkan oleh Paul C. W. Chu dan Maw-Kuen Wu pada 1987 [1]-[3]. Kali ini, bahan ini adalah seramik yttriumbarium-kuprum-oksida, atau $\mathrm{YBa}_{2} \mathrm{Cu}_{3} \mathrm{O}_{7}$, dengan suhu genting $95 \mathrm{~K}$. Penemuan demikian telah mencerahkan kemungkinan mempunyai pengalir lampau nyata dengan suhu genting pada suhu bilik. Nitrogen cecair adalah bahan pendingin kriogenik yang murah dan sedia diperolehi. Tambahan pula, pendingin kitar terbuka dan tertutup yang padat, murah dan bolehharap, turut sedia diperolehi. Kini, penggunaan dagangan keberaliran lampau kelihatan menjadi semakin meluas dan umum.

Semenjak itu, beberapa bahan berasaskan oksida kuprum yang mengalir lampau pada suhu tekanan ambien melebihi $120 \mathrm{~K}$ telah ditemui, seperti bismuth-strontium-kalsiumkuprum-oxida, thalium-barium-kalsium-kuprum-oxida dan merkuri-barium-kalsiumkuprum-oksida. Namun, mekanisme baru untuk keberaliran lampau diperlukan. Bahanbahan yang dikaji umum termasuklah $\mathrm{Bi}_{2} \mathrm{Sr}_{2} \mathrm{CaCu}_{2} \mathrm{O}_{8}\left(\mathrm{~T}_{c}=90 \mathrm{~K}\right), \mathrm{Bi}_{2} \mathrm{Sr}_{2} \mathrm{Ca}_{2} \mathrm{Cu}_{3} \mathrm{O}_{10}$ $\left(\mathrm{T}_{c}=110 \mathrm{~K}\right), \mathrm{Tl}_{2} \mathrm{Ba}_{2} \mathrm{CaCu}_{2} \mathrm{O}_{8}\left(\mathrm{~T}_{c}=110 \mathrm{~K}\right), \mathrm{Tl}_{2} \mathrm{Ba}_{2} \mathrm{Ca}_{2} \mathrm{Cu}_{3} \mathrm{O}_{10}\left(\mathrm{~T}_{c}=125 \mathrm{~K}\right)[4]$ dan $\mathrm{HgBa}_{2} \mathrm{Ca}_{2} \mathrm{Cu}_{3} \mathrm{O}_{8}\left(\mathrm{~T}_{c}=133 \mathrm{~K}\right)[3]$. Bahan terakhir ini turut mempunyai suhu genting yang lebih tinggi (150K) pada tekanan teramat tinggi [5]. Pengalir-pengalir lampau dengan suhu 


\section{Keberintangan AT}

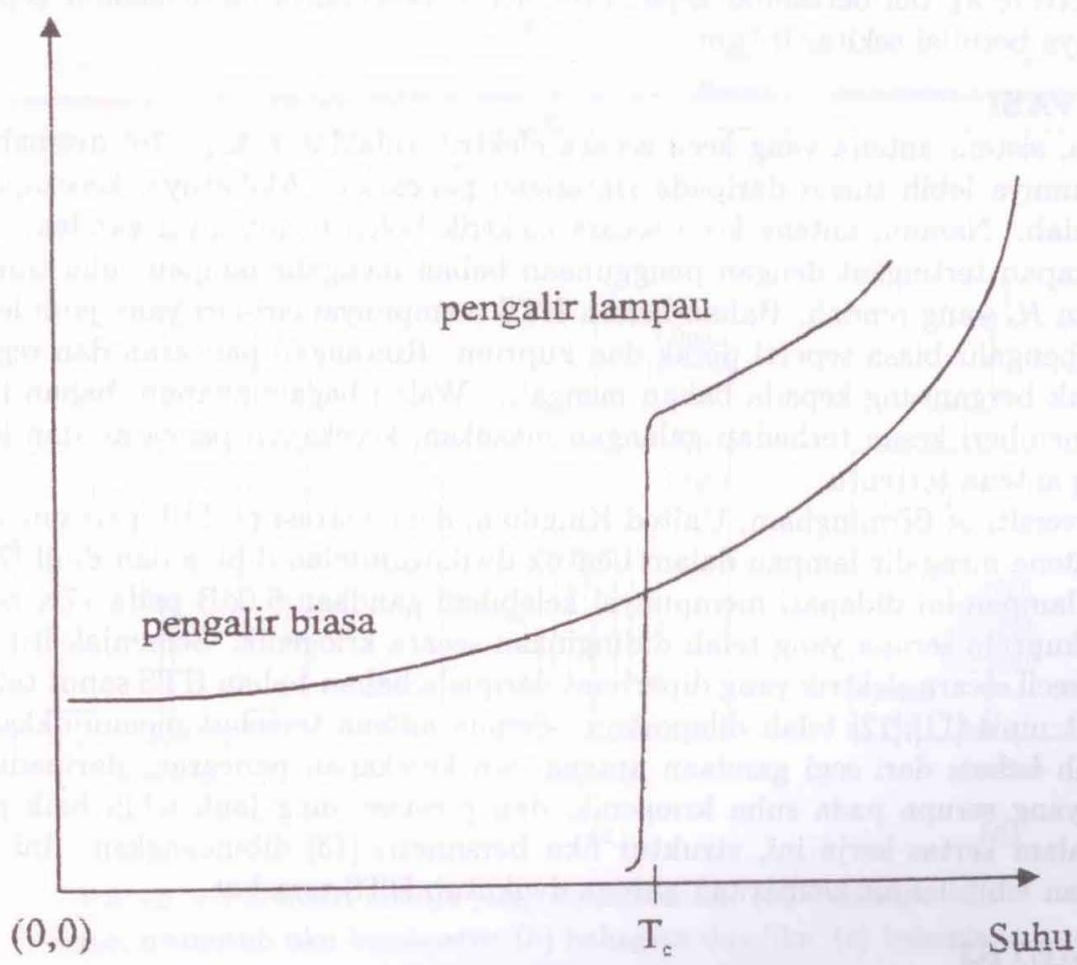

Rajah 1 Keberintangan AT suatu pengalir lampau dan pengalir biasa, sebagai fungsi suhu

genting melebihi $30 \mathrm{~K}$ adalah bahan-bahan oksida kuprum dan disebut pengalir lampau suhu tinggi, atau HTS.

Galangan permukaan $\left(Z_{s}\right)$ bahan pengalir lampau merupakan parameter penting. Ia menentukan mutu bahan mengalir lampau (atau malahan sebarang bahan) yang digunakan dalam penggunaan praktik. Ia ditakrifkan sebagai "galangan ciri yang dilihat oleh gelombang satah yang menuju permukaan rata bahan secara serenjang". Galangan ini terdiri daripada rintangan permukaan $\left(R_{s}\right)$ bersiri dengan regangan permukaan $\left(X_{s}\right)$. Bagi pengalir biasa, kedua-dua $R_{s}$ dan $X_{s}$ adalah sama nilai. Kedua-duanya mempunyai pergantungan frekuensi $f^{1 / 2}$. Walau bagaimanapun, $R_{s}$ bagi pengalir lampau mempunyai sandaran frekuensi $f^{2}$. Ini bermakna, suatu frekuensi melintas wujud apabila kedua-dua pengalir biasa dan pengalir lampau mempunyai $R_{s}$ yang sama. Di bawah frekuensi melintas ini, pengalir lampau mempunyai nilai $R_{s}$ yang diperbaiki berbanding pengalir biasa. $R_{s}$ adalah kuantiti yang biasa diukur menggunakan teknik seperti penyalun. Suatu bahan saput nipis yang baik boleh mempunyai frekuensi melintas melebihi $100 \mathrm{GHz}$ [6].

Bagi suatu pengalir lampau, $X_{s}$ adalah beraruhan. Aruhan setaranya $\left(L_{k}\right)$ dikenali sebagai aruhan kinetik. Ini menggambarkan tenaga kinetik pembawa-pembawa beraliran lam- 
pau. $X_{s}$ ini tak bersandar kepada frekuensi, tetapi ia bergantung kepada dalam penusukan London $\left(\lambda_{L}\right) \cdot \lambda_{L}$ adalah analogi kepada dalam kulit $(\delta)$ masalah resapan magnetik. Namun, tidak seperti $\delta, \lambda_{L}$ tak bersandar kepada frekuensi. Sebaliknya, ia bersandar kepada suhu. $\lambda_{L}$ biasanya bernilai sekitar $0.1 \mu \mathrm{m}$.

\section{MOTIVASI}

Umumnya, sistem antena yang kecil secara elektrik tidaklah cekap. Ini disebabkan kehilangan ohmnya lebih tinggi daripada rintangan pancaran. Akibatnya, kecekapan antena tetap rendah. Namun, antena kecil secara elektrik boleh mempunyai gandaan tertingkat dan kecekapan tertingkat dengan penggunaan bahan mengalir lampau suhu tinggi (HTS) disebabkan $R_{s}$ yang rendah. Bahan-bahan HTS mempunyai ciri-ciri yang jauh lebih hebat daripada pengalir biasa seperti perak dan kuprum. Rintangan pancaran dan regangan luarnya tidak bergantung kepada bahan mengalir. Walau bagaimanapun, bahan ini $\left(R_{s}\right.$ nya rendah) memberi kesan terhadap galangan masukan, kecekapan pancaran dan lebar jalur jenis-jenis antena tertentu.

Di Universiti of Birmingham, United Kingdom, demonstrasi praktik pertama dunia mengenai antena mengalir lampau dalam bentuk dwikutub telah dibina dan diuji [7]. Antena mengalir lampau ini didapati mempunyai kelebihan gandaan $6.0 \mathrm{~dB}$ pada $77 \mathrm{~K}$ berbanding struktur kuprum serupa yang telah didinginkan secara kriogenik. Semenjak itu, strukturstruktur kecil secara elektrik yang diperbuat daripada bahan-bahan HTS saput tebal [8]-[10] dan saput nipis [11],[12] telah dilaporkan. Semua antena tersebut menunjukkan prestasi yang lebih hebat, dari segi gandaan antena dan kecekapan pancaran, daripada struktur kuprum yang serupa pada suhu kriogenik, dan prestasi yang jauh lebih baik pada suhu bilik. Dalam kertas kerja ini, struktur liku bersimetri [13] dibincangkan. Ini telah merealisasikan lebih lanjut keupayaan antena dwikutub HTS tersebut.

\section{GEOMETRI}

Geometri dwikutub lelurus kuprum dan dwikutub-dwikutub liku mengalir lampau ditunjukkan dalam Rajah 2. Dwikutub lelurus $50.0 \mathrm{~mm}$ dengan lebar jejak $0.5 \mathrm{~mm}$ dihasilkan pada dielektrik politetrafluoroetilena (PTFE) bertetulang gentian kaca RT/Duroid 6010 $\left(\varepsilon_{r}=10.8\right.$ dan $1.27 \mathrm{~mm}$ tebal $)$, terlapik oleh $17.5 \mu \mathrm{m}$ tebal kuprum terenap elektro pada satu sisi. Pencorakan dan punaran dilakukan melalui teknik piawai foto litografi dan proses papan litar tercetak, secara berturutan. Masukan kepada penyambung SMA 50 ohm dilakukan daripada bawah melalui substratum.

Semua struktur mengalir lampau dibentuk daripada bahan YBCO saput nipis, terendap pada $1 \times 1 \mathrm{~cm}^{2}$ substratum magnesium oksida $(\mathrm{MgO})$ setebal $0.5 \mathrm{~mm}$ melalui proses ablasi laser. Setiap struktur mempunyai nisbah bidang 1.0 dan lebar jejak $78.0 \mu \mathrm{m}$. Jumlah panjang lengan ditetapkan pada $50.0 \mathrm{~mm}$. Dengan bertambahnya bahagian liku, antena ini boleh seterusnya dimodelkecilkan. Pencorakan dilakukan menggunakan teknik piawai punaran basah. Sambungan kepada penyambung masukan SMA $50 \mathrm{ohm}$ dibuat menggunakan epoksi perak terhadap petak perak (Ag) tersejat, yang secukupnya, di atas YBCO pada hujung talian masukan jalur sesatah.

\section{UJIKAJI DAN PENYELAKUAN BERANGKA}

Pengukuran pekali balikan $\left(\left|S_{11}\right|\right)$ dilakukan di dalam dewan tak bergema gelombang mikro, dengan kabel sambungan pada pelabuhan 1 penganalisis rangkaian HP8510C. Dwikutub lelurus diuji pada suhu bilik manakala antena mengalir lampau pada $77 \mathrm{~K}$. Antena mengalir lampau ini tenggelam seluruhnya dalam kotak polistirena berisi nitrogen cecair. 


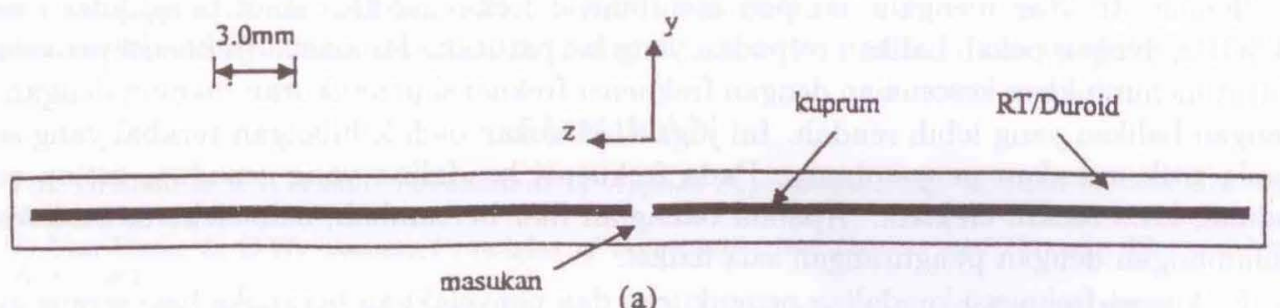

(a)

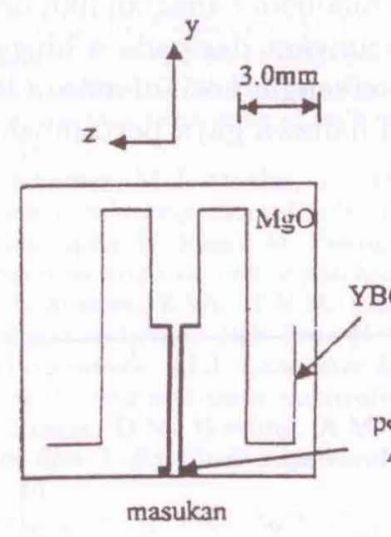

(b)

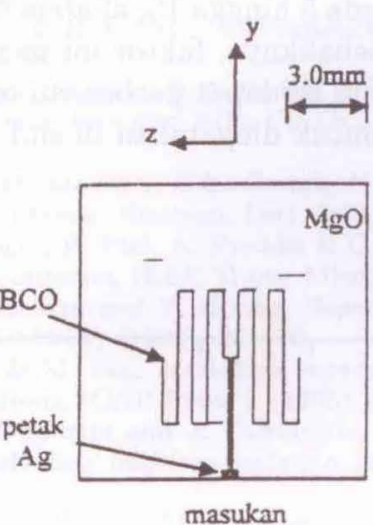

(c)

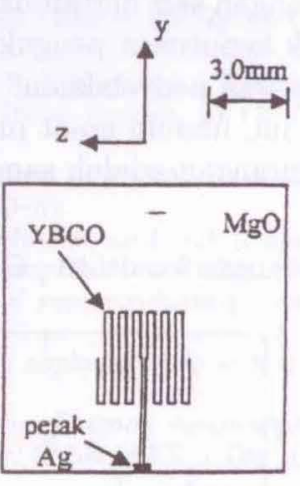

masukan

(d)

Rajah 2 Geometri antena yang direkabentuk: (a) dwikutub lelurus; dwikutub liku bersimetri: (b) bahagian dua liku, (c) bahagian empat liku, (d) bahagian enam liku

Kotak ini tidak langsung memberi kesan kepada prestasi antena disebabkan kebertelusan relatifnya yang hampir uniti [1]. Penyelakuan gelombang elektromagnet penuh telah dilakukan terhadap semua antena. Keputusan yang diperolehi dibincangkan di dalam bahagian seterusnya.

\section{KEPUTUSAN DAN PERBINCANGAN}

Pekali balikan dwikutub lelurus yang diukur pada salunan didapati bernilai $-19.4 \mathrm{~dB}$. Ini menunjukkan antena ini terpadan dengan baik. Frekuensi salunan asasi yang diukur berlaku pada $2.92 \mathrm{GHz}$. Walau bagaimanapun, pada frekuensi ini, dwikutub tersebut mempunyai saiz elektrik yang besar [14] $k_{0} a$ bernilai 1.38 ( $k_{0}$ adalah pemalar perambatan ruang bebas dan $a$ adalah jejari sfera terkecil yang melingkungi antena). Suatu antena hanya boleh dipertimbangkan sebagai kecil secara elektrik jika saiz elektriknya jauh lebih kecil daripada satu. Yang menariknya, dengan melikukan struktur memancar lalu membentuk dwikutub liku bersimetri, antena ini boleh dimodelkecilkan di samping mengekalkan frekuensi kendalian. Sebaliknya, frekuensi asasi salunan penyelakuan berlaku pada $3.0 \mathrm{GHz}$ dengan pekali balikan $-30.0 \mathrm{~dB}$. Saiz elektrik yang berhubungan adalah 1.54, iaitu masih besar secara elektrik. Keputusan pengukuran dan penyelakuan ternyata saling memuaskan. Kehilangan balikan amat rendah disebabkan oleh sejumlah kecil kehilangan masukan yang terabai. 
Semua struktur mengalir lampau mempunyai frekuensi kendalian pengukuran sekitar $3.0 \mathrm{GHz}$, dengan pekali balikan terpadan yang berpatutan. Frekuensi-frekuensi penyelakuan turut menunjukkan kesesuaian dengan frekuensi-frekuensi pengukuran, namun dengan kehilangan balikan yang lebih rendah. Ini juga disebabkan oleh kehilangan terabai yang serupa pada titik masukan penyambung. Pada frekuensi kendalian yang sepadan, setiap antena adalah kecil secara elektrik. Apabila bahagian liku bertambah, saiz elektrik berkurangan sehubungan dengan pengurangan saiz fizikal.

Frekuensi-frekuensi kendalian pengukuran dan penyelakuan berangka bagi semua antena yang diuji terhadap saiz elektrik berhubungan, ditunjukkan dalam Rajah 3. Faktor pengurangan saiz bertambah daripada 5 hingga 10, apabila bilangan bahagian liku bertambah, uftuk keputusan pengukuran. Sebaliknya, faktor ini meningkat daripada 4 hingga 9 , bagi keputusan penyelakuan. Walaupun terdapat perbezaan tersangat kecil di antara kedua-dua julat ini, namun amat menarik untuk dinyatakan di sini bahawa gaya pertambahan faktor pengurangan adalah sama.

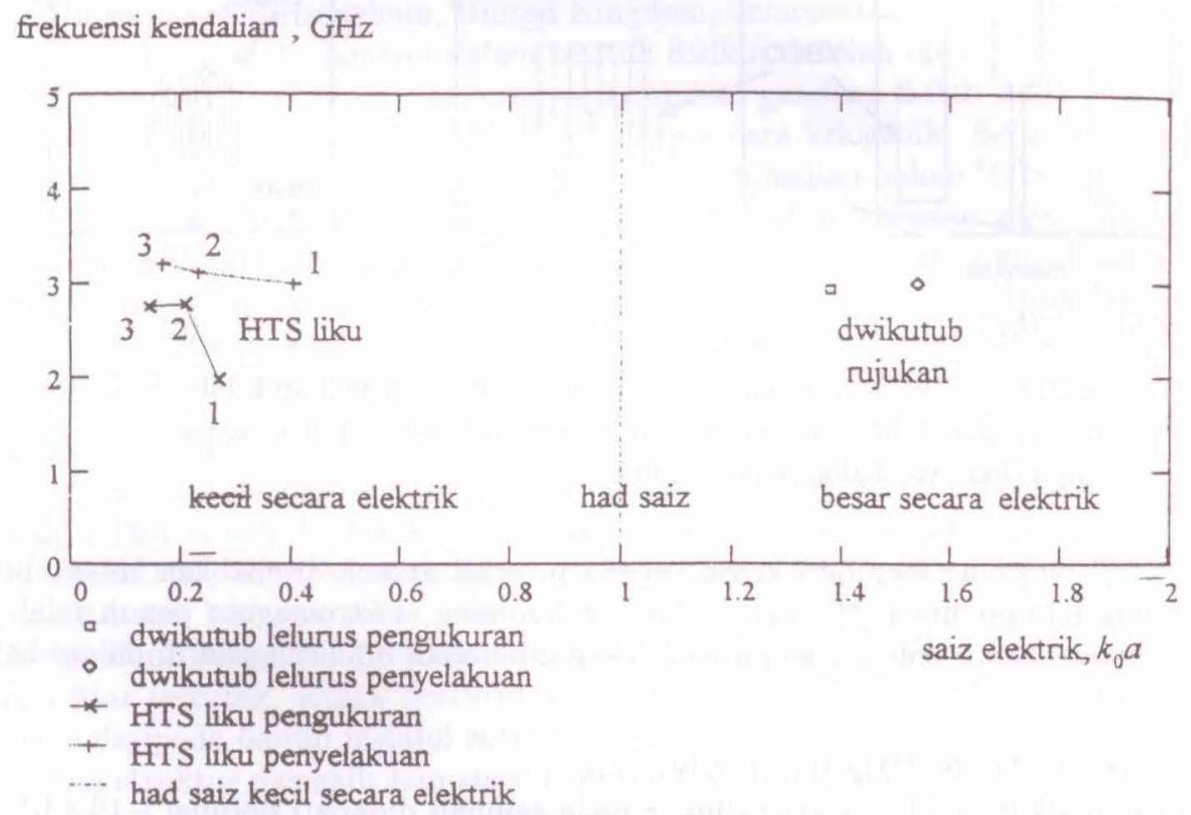

Rajah 3 Frekuensi kendalian hasil pengukuran dan penyelakuan berangka, terhadap saiz elektrik masing-masing

\section{KESIMPULAN DAN KERJA LANJUTAN}

Suatu set antena dwikutub liku bersimetri mengalir lampau suhu tinggi, yang kecil secara elektrik dan berkendali sekitar $3.0 \mathrm{GHz}$, sesuai untuk kegunaan terhad ruang telah ditunjukkan. Analisis sifat keberarahan lampau dan gandaan lampau antena tersebut menunjukkan keupayaan yang jauh mengatasi antena kuprum [13]. Corak pancaran medan jauh bagi antena liku bersimetri ini adalah serupa dengan corak pancaran medan jauh piawai bagi antena dwikutub lelurus. Pemodelkecilan antena dwikutub lelurus berupaya mengekalkan corak sinaran. Tambahan pula, pemodelkecilan antena berjaya menghasilkan 
prestasi yang memuaskan dengan menggunakan bahan HTS. Struktur liku ini boleh digabungkan membentuk antena tatasusunan yang dijangka berprestasi jauh lebih baik.

\section{RUJUKAN}

[1] T.P. Orlando \& K.A. Delin, Foundations of Applied Superconductivity, Addison-Wesley, Reading, Massachusetts, 1990.

[2] T. Van Duzer \& C.W. Turner, Principles of Superconductive Devices and Circuits, Elsivier, New York, 1981.

[3] Z-Y. Shen, High-Temperature Superconducting Microwave Circuits, Artech, Boston, 1995.

[4] W.G. Lyons \& R.S. Withers, Passive microwave devices applications of high temperature superconducting thin films, Microwave J. 11, (1990), 85-102.

[5] A. Schilling, M. Cantoni, G.D. Guo \& H.R. Ott, Superconductivity above $130 \mathrm{~K}$ in the $\mathrm{Hg}-\mathrm{Ba}-\mathrm{Ca}-\mathrm{Cu}$ O System, Nature 363 (1993), 56-58.

[6] N. McN. Alford, T.W. Button, G.E. Peterson, P. A. Smith, L. E. Davis, S. J. Penn. M. J. Lancaster \& $\mathrm{Z}$. Wu, Surface resistance of bulk and thick film $\mathrm{YBa}_{2} \mathrm{Cu}_{3} \mathrm{O}_{7-x}$, IEEE Trans. magnet. 27 (2) (1991), $1510-18$.

[7] S.K. Khamas, M.J. Mehler, T.S.M. Maclean, C.E. Gough, N.McN. Alford and M.A. Harmer, High Tc superconducting short dipole antenna, Electron. Lett. 24 (1988), 460-61.

[8] H. Chaloupka, N. Klein, M. Peiniger, H. Piel, A. Pischke \& G. Splitt, Miniaturized high temperature superconducting microstrip patch antenna, IEEE Trans. Microwave Theory Tech. 9 (1991), 1513-21.

[9] M.J. Lancaster, Z.Wu, T.S.M. Maclean and Y. Huang, Supercooled and superconducting small-loop and dipole antennas, IEE Proc-H 139(3) (1992), 264-70.

[10] L.P. Ivrissimtzis, M.J. Lancaster \& M. Esa, Miniature superconducting coplanar strip antennas for microwave and mm-wave applications, ICAP Proc. 1 (1995), 391-95.

[11] R.J. Dinger, D.M. Bowling, A.M. Martin and J. Talvacchio, Radiation efficiency measurements of a thin-film $\mathrm{Y}-\mathrm{Ba}-\mathrm{Cu}-\mathrm{O}$ superconducting half-loop antenna at 500MHz, IEEE MTT-S Dig. (1991), $1243-46$.

[12] H. Chaloupka, H. Piel, A. Pishke, G. Gieres, M. Peiniger, L. Schultz, M. Bode \& J. Schubert, Hightemperature superconducting meander antenna, IEEE MTT-S Dig. (1992), 189-92.

[13] M. Esa, Electrically Small high-temperature Superconducting Y-Ba-Cu-O Meander Dipole Antennas for Space-limited Applications, PhD thesis, Unpublished dissertation, University of Birmingham, England, August 1996.

[14] J.D. Kraus, Antennas, McGraw-Hill, New York, 1988. 